\title{
Cost-effectiveness of drug-management of hypertension among patients in selected secondary facilities in Nigeria: Empirical evidence for rational prescription choices
}

\author{
Costo-efectividad del manejo farmacológico de la hipertensión en pacientes de entidades \\ de segundo nivel seleccionados en Nigeria: evidencia empírica para elecciones \\ racionales de formulación
}

Irikefe P. Obiebi* and Henry O. Aiwuyo

Delta State University Teaching Hospital, Oghara, Delta State, Nigeria

\begin{abstract}
Background: The financial burden of managing hypertension in developing countries, where most of healthcare is funded out-of-pocket, is huge and poor patients cannot sustainably afford it. This is a challenge for most people, especially in sub-Saharan Africa with poor health indices, and this informed the investigation of the cost-effectiveness of anti-hypertensive drugs. Methodology: This was essentially a before-and-after study without control, in which blood pressure was assessed after commencing treatment with anti-hypertensive drugs among hypertensive patients. A systematic sampling technique was employed to recruit 320 participants from new patients attending cardiology clinic and admitted into the wards in four secondary health facilities offering specialized medical services in Nigeria. Results: The median cost of drug treatment of hypertension per week was N977.50; this cost was much lower for monotherapy than combined therapy. Similarly, the median costs of treatment per decrease in systolic and diastolic blood pressures were higher with combined therapy than monotherapy. The median cost of treatment per decrease in systolic blood pressure was higher than diastolic pressure. Diuretics had the most cost per decrease in diastolic blood pressure, while ACEI had the highest costs per decrease in systolic blood pressure and the highest cost per week. The lowest cost per week was recorded for beta-blockers, which also had the lowest cost per decrease in diastolic blood pressure and similar to the average cost per unit decrease in systolic blood pressure for centrally acting drugs. Conclusion: There was a significant improvement in blood pressure three months following the start of anti-hypertensive drugs. Beta-blockers appeared most cost-effective while diuretics as well as ACE inhibitors were the least. Monotherapy costs less per week, but it could not be proved from this study that it was more cost-effective than combined therapy.
\end{abstract}

Key words: Cost-effectiveness. Hypertension. Drug management. Prescription drugs.

\section{Resumen}

Antecedentes: la carga financiera del manejo de la hipertensión en países en vías de desarrollo, donde la mayoría de la atención en salud es financiada por cuenta propia, es enorme, y los pacientes de escasos recursos no lo pueden

Correspondence:

*Irikefe P. Obiebi

E-mail: irikefewhite@yahoo.com
Date of reception: 10-07-2018

Date of acceptance: 06-05-2020

DOI: 10.24875/RCCAR.M21000008
Available online: 19-03-2021

Rev Colomb Cardiol. 2021;28(1):45-52

www.rccardiologia.com

0120-5633 / @ 2020 Sociedad Colombiana de Cardiología y Cirugía Cardiovascular. Published by Permanyer. This is an open access article under the CC BY-NC-ND license (http://creativecommons.org/licenses/by-nc-nd/4.0/). 
costear de manera sostenible. Este es el reto para la mayoría de las personas, especialmente en África subsahariana que tiene indicadores de salud pobres, y esto fundamentó la investigación de la costo-efectividad de las drogas antihipertensivas. Metodología: esencialmente un estudio antes-después, sin control, en el cual se evaluó la tensión arterial luego de iniciar tratamiento con antihipertensivos en pacientes hipertensos. Se empleó una técnica de muestreo sistemático para reclutar 320 participantes de entre los pacientes nuevos atendidos en consulta de cardiología y hospitalizados en cuatro entidades de salud de segundo nivel en Nigeria. Resultados: el costo medio semanal del tratamiento farmacológico de la hipertensión fue de N977.50; este costo fue mucho menor para la monoterapia que para la terapia combinada. Asimismo, el costo medio de tratamiento por reducción en las cifras de tensión arterial sistólica y diastólica fue mayor con la terapia combinada que con la monoterapia. El costo medio de tratamiento por reducción en la tensión arterial sistólica fue mayor que para la tensión diastólica. Los diuréticos tuvieron el mayor costo por reducción en tensión arterial diastólica, mientras que los IECA tuvieron el mayor costo por reducción en tensión arterial sistólica y el costo más alto por semana. El costo más bajo por semana se registró para los beta-bloqueadores, los cuales también tuvieron el menor costo por reducción en la tensión arterial diastólica y un costo similar al promedio por unidad de reducción en la tensión arterial sistólica para los medicamentos de acción central. Conclusión: hubo una mejoría significativa en la tensión arterial luego de tres meses del inicio de drogas antihipertensivas. Los beta-bloqueadores parecieron ser los más costo-efectivos, mientras que los diuréticos e inhibidores de ECA fueron los menos costo-efectivos. La monoterapia costó menos por semana pero no se pudo comprobar con este estudio que fuera más costo-efectivo que la terapia combinada.

Palabras clave: Costo-efectividad. Hipertensión. Manejo de medicamentos. Prescripción de medicamentos.

\section{Introduction}

Persistently elevated arterial blood pressure is usually referred to as hypertension ${ }^{1}$. Nonetheless, end-organ damage and mortality tend to increase through rising levels of blood pressure. Thus, the onset of cardiovascular disease may be subtle and undetected even before a diagnosis of pre-hypertension or hypertension is made ${ }^{2,3}$. Further, people with controlled blood pressure may develop cardiovascular complications such as congestive cardiac failure or stroke ${ }^{2}$; more so, elevated blood pressure could be a manifestation of pre-existing cardiovascular disease ${ }^{4}$. Nonetheless, timely and proper treatment with anti-hypertensive drugs can reduce the risk of cardiovascular events ${ }^{5-7}$, a fact that has been highlighted in a randomized trial of hypertensive patients at high risk of cardiovascular disease ${ }^{7,8}$. Further, among patients with complications, appropriate use of anti-hypertensive drugs has been known to reverse end-organ damage, prevent further damage $^{6}$, and thus, prolong life while preventing cardiovascular events?

In many underdeveloped climes, there seems to be a paucity of guidelines as well as protocol for managing hypertension alongside comorbidities ${ }^{9}$. Contrarily, in developed countries where there is adequate political will and commitment from non-governmental agencies to improving health indices, this hurdle, most likely, has been surmounted. Consequently, the exigency to adopt a treatment protocol for hypertension which is not only pharmacologically appropriate and cost-effective but also consistent with our local peculiarities cannot be over-emphasized.

Anti-hypertensive drugs, in their multitudinous forms, work synergistically or solely to reduce blood pressure $^{10}$. This has been the cornerstone of treating patients with various degrees of elevated blood pressure as well as the treatment of hypertensive crisis. Nonetheless, the treatment certainly does not come without a cost and ${ }^{11}$ is responsible for a chunk of the gross domestic product of most developed countries with apparent universal health coverage.

The financial burden in developing countries, where most of healthcare is funded out-of-pocket, is huge, and poor patients cannot sustainably afford it. Therefore, complications of hypertension as well as other cardiovascular morbidities are commonplace. ${ }^{9}$ We consider this a challenge for most people, especially in sub-Saharan Africa, with poor health indices. Each anti-hypertensive drug has its own mode of action, effectiveness and $\cos ^{12}$. It is, therefore, expedient to choose the requisite medication to actualize the expected pharmacological response without disregarding the financial burden on the patient.

Several studies have investigated the economic and clinical benefits accruing from appropriate administration of anti-hypertensive drugs; however, a dearth of evidence on the pharmacoeconomics of each class of anti-hypertensive agent is prevalent, not only in Nigeria 
but also in other developing nations ${ }^{11,13-15}$. Amira and Okubadejo in 2006 and llesanmi et al. ${ }^{16,17} 6$ years later analyzed the cost-effectiveness of anti-hypertensive drugs; however, they used the proportion of patients who attained optimal blood pressure control as denominator. More recently, in 2015, Bakare et al. reported the average cost of anti-hypertensive treatment per month among hypertensive patients in a teaching hospital in Nigeria $^{12}$; nonetheless, the cost-effectiveness of these medications was not elucidated in the study. We hypothesized that in the light of current economic vagaries, using a mean reduction in blood pressure would provide some clarity on the cost of precise, measurable, and time-specific targeted blood pressure control from the anti-hypertensive drugs commonly available to prescribing physicians as well as other healthcare providers. The findings of this study would provide a basis for physicians to develop prescription choices that are within the reach of the poor with the current hypertension guideline as the pivot for its implementation.

\section{Materials and methods}

\section{Study area, population, and design}

This study was conducted to assess blood pressure control after commencing treatment with anti-hypertensive drugs among hypertensive patients in four secondary health facilities offering specialized medical services in Nigeria. Blood pressure was measured before commencing treatment. The design of the study was essentially a before-and-after study without a control group.

\section{Ethical consideration}

Ethical clearance was obtained from Research and Ethics Committee of State Hospitals Management Board. Written informed consent was obtained from study participants who voluntarily took part in the study.

\section{Sampling technique}

A total of 320 patients were recruited from all the centers over a 4-month period. A systematic sampling technique was employed to recruit study participants. The number of new patient expected at all the centers during the recruitment phase of the study was $960-$ estimated from the year preceding the study-. Each week, 5 out of 15 new patients attending the cardiology clinic and admitted into the wards at each center were selected with a sampling interval of three (derived by dividing the estimated target population size of 960 by the sample size of 320); the first patient for each week was selected from the clinic or ward register with a simple random technique by balloting.

\section{Selection criteria}

All hypertensive patients had their blood pressure taken at rest and measurement repeated on a subsequent visit to confirm hypertension. However, those with comorbidities and others who declined to give consent were excluded from the study.

\section{Recruitment and training of research assistants}

Four research assistants who were recruited for the purpose of this study took part in a short training session involving blood pressure measurement, review of questionnaire, education on patient confidentiality, and informed consent.

\section{Data management}

\section{Data collection}

\section{SCREENING}

This was scheduled to identify potential non-adherent patients and those who were no longer interested in the study. Patients had two weeks during which they were counseled on strategies to circumvent challenges with treatment adherence. The patients' compliance was ascertained by recall questions and those whose compliance was not up to $90 \%$ were excluded from the study.

\section{Pre-treatment blood pressure}

Blood pressure was measured using an appropriate sphygmomanometer cuff size applied to the right arm of the patients while they sat upright. The patients had to rest for about $7 \mathrm{~min}$ before their blood pressures were taken with a typical mercury sphygmomanometer. A repeat measurement was taken at the end of the interview and the average of the two recorded.

\section{INTERVIEW}

A semi-structured interviewer-administered questionnaire was applied to collect data on sociodemographic 
characteristics, history of hypertension, cost of drug per week, and type of anti-hypertensive drugs used 2 weeks into the commencement of treatment with anti-hypertensive drugs.

\section{FOLLOW-UP}

Three months after commencement of treatment with anti-hypertensive drugs, blood pressure measurement was taken for each patient.

\section{DATA ANALYSIS}

Collected data were sorted and entered into the spreadsheet of Statistical Package for the Social Sciences (SPSS) version 22 (IBM Corp., Armonk NY, USA) for analysis. Categorical variables were presented in percentages, while continuous variables in means ( \pm standard deviations). Students' and paired $t$-test were applied to assess the difference between means. Mann-Whitney $U$ tested the difference in between medians. The level of statistical significance was set at $\mathrm{p}<0.05$ for Mann-Whitney $\mathrm{U}$ and $t$ tests.

\section{Cost-efFECTIVENESS ANALYSIS}

Only direct cost of purchasing anti-hypertensive drugs was considered. Cost-effectiveness was computed using cost-effectiveness ratio: Cost per unit decrease in blood pressure for diastolic and systolic blood pressure, classes of anti-hypertensive drugs, as well as monotherapy and combined treatment. Annual cost was projected from cost per week by multiplied by 52 and further converted to dollars at an exchange rate of $\$ 1=\mathrm{N} 360.05$.

\section{Results}

Of all 320 participants, only 282 were included in the analysis. Twenty were lost to follow-up and 18 were excluded for incomplete data; this gave a response rate of $88.1 \%$. Three-fifths $(61.0 \%)$ of all participants had no formal education, two-fifths (42.6\%) were aged 60 years and above, males were more than female $(56.0 \%$ vs. $44.0 \%$ ), and the majority were married (Table 1 ).

Proportion of participants with normal blood pressure and pre-hypertension post-treatment was $27.3 \%$ and $13.8 \%$, and there was a $49 \%$ decrease in stage 2 hypertension after treatment; however, treatment outcomes differed significantly from pre-treatment proportions $(p<0.001)$ (Table 2$)$. Mean decrease in systolic and diastolic hypertension were $25.23(95 \% \mathrm{Cl}$ :
Table 1. Sociodemographic characteristics of patients

\begin{tabular}{|l|l|r|}
\hline Variables & Categories & Frequency (\%) \\
\hline Age group & $18-29$ & $6(2.2)$ \\
\hline & $30-39$ & $34(12.1)$ \\
\hline & $40-49$ & $50(17.7)$ \\
\hline Sex & $50-59$ & $72(25.5)$ \\
\hline \multirow{2}{*}{ Marital status } & 60 and above & $120(42.6)$ \\
\hline & Single & $158(56.0)$ \\
\hline & Married & $124(44.0)$ \\
\hline Semale & $18(6.4)$ \\
\hline Education & Widowed & $196(69.5)$ \\
\hline & No formal education & $9(3.2)$ \\
\hline & Primary & $59(20.9)$ \\
\hline & Secondary & $172(61.0)$ \\
\hline & Tertiary & $31(11.0)$ \\
\hline
\end{tabular}

22.62-7.83) and 10.14 (95\% Cl: 8.60-11.69) $\mathrm{mm} \mathrm{Hg} 3$ months following commencing anti-hypertensive therapy. The decrease in blood pressures (systolic and diastolic) was far higher for combined therapy $(25.44 \mathrm{~mm}$ $\mathrm{Hg}$ ) than monotherapy $(10.05 \mathrm{~mm} \mathrm{Hg})$; however, the mean difference was not statistically significant $(p$ $0.211,0.195$ ) (Table 3). The median cost of treating (drug-management) hypertension per week was $\$ 2.72$ (culminating in an annual cost of $\$ 141.44]$ ); this weekly cost was much lower for monotherapy (\$0.78) than combined therapy (\$2.74). Similarly, the median costs of treatment per decrease in systolic and diastolic blood pressures were higher with combined therapy $(\$ 0.07$ and $\$ 0.04$ ) than monotherapy ( $\$ 0.17$ and $\$ 0.12$ ). The median cost of treatment per decrease in systolic blood pressure was higher than that in diastolic pressure. However, the difference in median values was not significant ( $p>0.05$ ) (Table 4). The mean cost of treatment per week was significantly lower with monotherapy than combined therapy. However, the mean costs of treatment per decrease in diastolic blood pressures were almost the same for combined therapy and monotherapy. The mean cost of treatment per decrease in systolic blood pressure was lower than diastolic pressure (Table 5). Diuretics had the most cost per decrease in diastolic blood pressure, while ACEI had the highest 
Table 2. Staging and types of hypertension

\begin{tabular}{|l|l|c|c|}
\hline & & Before treatment & After treatment \\
\hline JNC7 staging & Stage 1 & $51(18.1)$ & $68(24.1)$ \\
\hline & Stage 2 & $179(63.5)$ & $40(14.2)$ \\
\hline & Isolated systolic or diastolic Hypertension & $44(14.9)$ & $54(15.2)$ \\
\hline & Normal BP & $0(0.0)$ & $78(27.7)$ \\
\hline & Pre-hypertension & $0(0.0)$ & $40(14.2)$ \\
\hline Crisis & $8(2.5)$ & $2(0.7)$ \\
\hline Drug regimen & & $* \chi^{2}=213.273$ & $<0.001$ \\
\hline Average number of drugs & Monotherapy & $6(2.2)$ & $276(97.8)$ \\
\hline & Combination & $3.49 \pm 1.02$ & 3 \\
\hline
\end{tabular}

SD: standard deviation.

Table 3. Paired differences in treatment outcome with anti-hypertensive drugs

\begin{tabular}{|l|c|c|c|c|c|}
\hline Blood pressure & At diagnosis & 3 months & Mean decrease in BP (95\%CI) & t-test & $\mathbf{p}^{1}$ value \\
\hline SBP & $170.14 \pm 23.85$ & $144.91 \pm 18.78$ & $25.23(22.62-27.83)$ & 19.085 & $<0.001$ \\
\hline DBP & $98.90 \pm 14.63$ & $88.76 \pm 12.67$ & $10.14(8.60-11.69)$ & 12.940 & $<0.001$ \\
\hline & \multicolumn{2}{|c|}{ Mean difference between monotherapy and combined therapy } & & $\mathbf{p}^{2}$ \\
\hline & Monotherapy & Combined therapy & & 0.211 \\
\hline Decrease in SBP & 11.50 & 25.44 & -13.94 & 0.195 \\
\hline Decrease in DBP & 1.75 & 10.05 & -8.55 & \\
\hline
\end{tabular}

${ }^{1} \mathrm{p}$ value for paired $t$ test; $\mathrm{Cl}$ : confidence interval of mean difference; $\mathrm{p}^{2}$ : $\mathrm{p}$-value for difference between two means; SBP: systolic blood pressure; DBP: diastolic blood pressure.

Table 4. Median cost (\$) of treatment per unit decrease in blood pressure $(\mathrm{mm} \mathrm{Hg}$ )

\begin{tabular}{|l|c|c|c|c|}
\hline Variable & All & Monotherapy & Combined therapy & $\mathbf{p}^{1}$ value \\
\hline Total cost/week $(\$)$ & 2.72 & 0.78 & 2.74 & 0.371 \\
\hline Average cost per unit decrease in SBP (\$) & 0.17 & 0.07 & 0.17 & 0.614 \\
\hline Average cost per unit decrease in DBP (\$) & 0.12 & 0.04 & 0.12 & 0.614 \\
\hline
\end{tabular}

${ }^{1} \mathrm{p}$ value for Mann-Whitney U test for difference in median of two independent samples; SBP: systolic blood pressure; DBP: diastolic blood pressure.

costs per decrease in systolic blood pressure and the highest cost per week. The lowest cost per week was recorded for beta-blockers which also had the lowest cost per decrease in diastolic blood pressure and similar to the average cost per unit decrease in systolic blood pressure for centrally acting drugs (Fig. 1). 
Rev Colomb Cardiol. 2021;28(1)

Table 5. Mean cost of treatment per unit decrease in blood pressure

\begin{tabular}{|l|c|c|c|c|c|}
\hline Variable & All therapy & Monotherapy & Combined therapy & Mean difference & $\mathbf{p}^{1}$ value \\
\hline Total cost/week (\$) & 3.08 & 1.29 & 3.11 & -1.82 & 0.024 \\
\hline Average cost per unit decrease in SBP (\$) & 0.12 & 0.11 & 0.13 & -0.02 & 0.871 \\
\hline Average cost per unit decrease in DBP (N) & 0.30 & 0.74 & 0.31 & 0.43 & 0.062 \\
\hline
\end{tabular}

'p value for two independent sample $t$ test; SBP: systolic blood pressure; DBP: diastolic blood pressure.

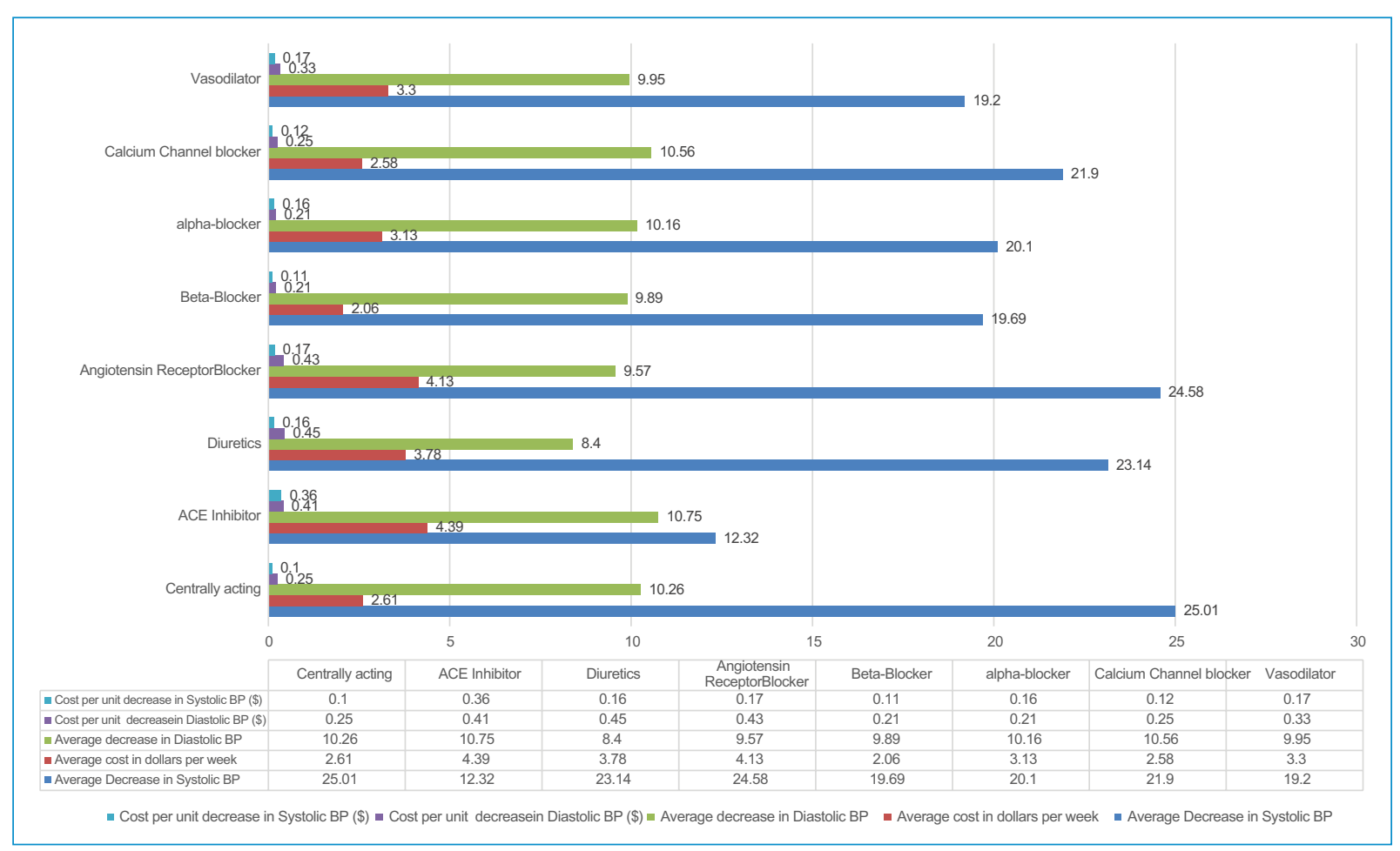

Figure 1. Average cost $(\$)$ of antihypertensive drugs per unit decrease in blood pressure.

\section{Discussion}

The results of this study revealed a significant reduction in blood pressure 3 months after being on anti-hypertensive drugs. This not only emphasizes the fact that the medications for treating high blood pressure are efficacious but also effective in achieving normal blood pressure as a large proportion of participants achieved normal blood pressure in the post-treatment phase. Several previous studies have also corroborated these findings on the efficacy of anti-hypertensive in achieving blood pressure reduction $8,18,19$.

A greater proportion of patients had to be on multiple anti-hypertensive drugs to attain blood pressure control. Achieving blood pressure control could prove difficult in many patients due to a plethora of factors involving non-adherence to lifestyle modification, continuing on a high salt diet, monogenic forms of hypertension, and other presentations such as secondary hypertension. Thus, it is not unforeseen to have a multidrug regimen administered to patients. Combination therapy, rather than monotherapy, is strongly advocated for in the National Institute for Health and Care Excellence $^{10}$, which probably acknowledges that administration of several medications will suffice for most patients because of the multifactorial nature of the hypertensive state ${ }^{1}$.

The significant improvement in blood pressure within 3 months buttresses the efficacy of the medications currently in use; more so because anti-hypertensive drugs tend to peak in plasma well before 1 week and it is valuable in the prevention of hypertensive crisis. 
However, there was no difference in systolic and diastolic blood pressures between patients on monotherapy and those on combination therapy. This observation may contradict common knowledge where it is expected that combination therapy should be more effective than monotherapy ${ }^{12}$. A very likely reason for this is not far-fetched as the proportion of hypertensive patients on monotherapy was too small, and thus, too underpowered to elicit a difference between single and combination therapy. Nevertheless, most patients with borderline hypertension, as well as those at stage one hypertension, can do well on a single therapy, and thus, it may be superfluous to use combination therapy in these instances?

Extrapolated annual cost per patient was higher than that reported from a previous study conducted in the $U^{20}$. Thus, patients in our locale are haplessly faced with the reality of paying a higher sum than those in the UK with much better health coverage. The cost of lowering systolic blood pressure by $1 \mathrm{~mm} \mathrm{Hg}$ was N61.31 (equivalent to $\$ 0.17$ ) and amounts to $\$ 8.85$ per annum. In contrast, a similar study reported a much higher cost of $\$ 33.27^{21}$, probably because it included direct as well as indirect costs of treatment. Anti-hypertensive drugs belonging to the classes of centrally-acting drugs were the most effective and cost-effective in reducing systolic blood pressure. Similarly, a previous study reported a centrally-acting anti-hypertensive drug as the most cost-effective ${ }^{17}$. Whereas ACE inhibitors reduced diastolic blood pressure better than others, beta-blockers cost the least amount and was the most cost-effective in reducing diastolic BP. Contrariwise, a previous study conducted in Nigeria reported diuretics to be the most cost-effective, although cost-effectiveness was computed based on the proportion of patients who attained a target blood pressure control ${ }^{17}$. Even though long-term compliance with anti-hypertensive treatment was not assessed in this study, the 3-month cost-effective analysis indicates that it would be better to adopt cost-effective treatment since hypertension is usually a chronic ailment ${ }^{20}$. Circumventing irrational prescription of anti-hypertensive drugs would also imply that cost-effectiveness be given priority in the preference for drug-management of hypertension.

The major limitations of this study were that personal income and occupations of patients were not reported. Furthermore, likely side-effects of anti-hypertensive drugs were not reported and indirect costs of treatment were not considered.

\section{Conclusion}

Blood pressure improved significantly 3 months following the start of anti-hypertensive drugs. Beta-blockers appeared most cost-effective while diuretics as well as ACE inhibitors were the least cost-effective. Monotherapy costs less per week, but it could not be proved from this study that it was more cost-effective than combined therapy. Prescription of anti-hypertensive drugs should be evidence-based and driven by cost-effectiveness for the all-inclusive well-being of hypertensive patients.

\section{Conflicts of interest}

The authors declare no competing or conflicts of interest.

\section{Funding}

This research did not receive any specific grant from funding agencies in the public, commercial, or not-forprofit sectors.

\section{Acknowledgments}

Our sincere appreciation goes to our senior colleagues for proof-reading the article.

\section{Ethical disclosures}

Protection of human and animal subjects. The authors declare that no experiments were performed on humans or animals for this study.

Confidentiality of data. The authors declare that they have followed the protocols of their work center on the publication of patient data.

Right to privacy and informed consent. The authors have obtained the written informed consent of the patients or subjects mentioned in the article. The corresponding author is in possession of this document.

\section{References}

1. Giles TD, Materson BJ, Cohn JN, Kostis JB. Definition and classification of hypertensionition and io. J Clin Hypertens. 2009;11:611-4.

2. Bidani $A K$, Griffin KA. Basic science: hypertensive target organ damage. J Am Soc Hypertens. 2015;9:235-7.

3. Gokce N, Holbrook M, Duffy SJ, Demissie S, Cupples LA, Biegelsen E, et al. Effects of race and hypertension on flow-mediated and nitroglycerin-mediated dilation of the brachial artery. Hypertension. 2001;38:1349-54.

4. Giles TD, Berk BC, Black HR, Cohn JN, Kostis JB, Izzo JL, et al. Expanding the definition and classification of hypertension. J Clin Hypertens. 2005;7:505-12.

5. Expert Panel on Detection, Evaluation, and Treatment of High Blood Cholesterol in Adults. Third report of the national cholesterol education 
Rev Colomb Cardiol. 2021;28(1)

program (NCEP) expert panel on detection, evaluation, and treatment of high blood cholesterol in adults (adult treatment panel III) final report. Circulation. 2002;106:3134-21.

6. Armstrong C. JNC 8 guidelines for the management of hypertension in adults. Am Fam Physician. 2014;90:503-4.

7. Chobanian AV, Bakris GL, Black HR, Cushman WC, Green LA, Izzo JL Jr., et al. The seventh report of the joint national committee on prevention, detection, evaluation, and treatment of high blood pressure. JAMA. 2003;289:2560-71.

8. Gueyffier F, Bulpitt C, Boissel JP, Schron E, Ekbom T, Fagard R, et al. Antihypertensive drugs in very old people: a subgroup meta-analysis of randomised controlled trials. Lancet. 1999;353:793-6.

9. Rachana PR, Anuradha HV, Shivamurthy M. Anti-hypertensive prescribing patterns and cost analysis for primary hypertension: a retrospective study. J Clin Diagn Res. 2014;8:19-22.

10. National Institute of Health Care Excellence. Hypertension-in-adults-diag nosis-and-management. London: National Institute of Health Care Excellence; 2011. Available from: https://www.nice.org.uk/guidance/cg127.

11. Rosendaal NT, Hendriks ME, Verhagen MD, Bolarinwa OA, Sanya EO, Kolo PM, et al. Costs and cost-effectiveness of hypertension screening and treatment in adults with hypertension in rural Nigeria in the context of a health insurance program. PLoS One. 2016;11:e0162421.

12. Bakare $O Q$, Goodman $O$, Kuyinu YA, Wright OK, Adeniran A, Odusanya OO, et al. Antihypertensive use, prescription patterns, and cost of medications in a teaching hospital in Lagos, Nigeria. Niger J Clin Pract. 2016;19:668-72.

13. Okeahialam BN, Adeniyi MA. Economic benefit of back titration in the treatment of hypertension in Jos, Nigeria. Clin Outcomes Res. 2017;9:207-10.
14. Carbonell Gl, Rodrell Glc beD Ro PA, Balcindes AS, Aroche GR Cost-effectiveness of the antihypertensive treatment in patients of 2 health areas from Santiago de Cuba municipality in 2013. MediSan. 2016;20:5079-88.

15. Ekwunife OI, Aguwa CN. Cost-effectiveness analysis of interventions to improve control of high blood pressure in low resource settings: the case of Nigeria. Cardiol Angiol. 2014:2:92-101.

16. Amira C, Okubadejo N. Antihypertensive pharmacotherapy in a developing economy: pattern, acquisition, and conformity to international guideline in a tertiary-care setting. J Hum Hypertens. 2006;20:894-7.

17. Ilesanmi OS, Ige OK, Adebiyi AO. The managed hypertensive: the costs of blood pressure control in a Nigerian town. Pan Afr Med J. 2012; 8688:96-105.

18. Nissen SE, Tuzcu EM, Libby P, Thompson PD, Ghali M, Garza D, et al. Effect of antihypertensive agents on cardiovascular events in patients with coronary disease and normal blood pressure: the CAMELOT study: a randomized controlled trial. JAMA. 2004;292:2217-25.

19. Julius S. Outcomes in hypertensive patients at high cardiovascular risk treated with regimens based on valsartan or amlodipine: the VALUE randomised trial. Lancet. 2004;363:2022-31.

20. Esposti LD, Di Martino M, Saragoni S, Sgreccia A, Capone A, Buda S, et al. Pharmacoeconomics of antihypertensive drug treatment: an analysis of how long patients remain on various antihypertensive therapies. $J$ Clin Hypertens. 2004;6:76-83.

21. Polgreen LA, Han J, Carter BL, Ardery GP, Coffey CS, Chrischilles EA et al. Cost-effectiveness of a physician-pharmacist collaboration intervention to improve blood pressure control. Hypertension. 2015;66:1145-51. 